\title{
The impact of racially-motivated housing discrimination on allostatic load among Indigenous university students
}

\section{Cheryl Currie ( $\square$ cheryl.currie@uleth.ca )}

University of Lethbridge https://orcid.org/0000-0001-5366-0641

\section{Takara A. Motz}

University of Lethbridge Faculty of Health Sciences

Jennifer L Copeland

University of Lethbridge Faculty of Arts and Science

\section{Research article}

Keywords: Racial discrimination; housing discrimination; allostatic load; Indigenous

Posted Date: August 28th, 2019

DOl: https://doi.org/10.21203/rs.2.12992/v1

License: @ (i) This work is licensed under a Creative Commons Attribution 4.0 International License. Read Full License

Version of Record: A version of this preprint was published at Journal of Urban Health on June 1st, 2020. See the published version at https://doi.org/10.1007/s11524-020-00446-6. 


\section{Abstract}

Background Allostatic load (AL) is a preclinical marker of the pathophysiologic processes that precede the onset of disease. The goal of this study was to examine the association between racially-motivated housing discrimination and AL score within a sample of Indigenous university students.

Methods Data for this cross-sectional study were collected from Indigenous adults attending university in a small city in western Canada between 2015 and 2017 ( $N=104$; Mean age = 27.8 years). An item adapted from the Experience of Discrimination Scale was to assess racially-motivated housing discrimination in the past 12 months. AL was measured as a composite of 7 biomarkers assessing neuroendocrine, cardiovascular, metabolic, and immune system function. Bias-corrected and accelerated bootstrapped linear regression models were used to examine associations adjusting for age, income, parenthood, and other situations in which discrimination had been experienced.

Results Indigenous university students who experienced racially-motivated housing discrimination in the past year ( $16.8 \%$ of the sample) had an average AL score of approximately 4, which was almost double that of their peers who had not. In an adjusted model. racially-motivated housing discrimination was associated with a- 1.5 point increase in AL score. This model explained $35 \%$ of the adjusted variance in AL score, of which racially-motivated housing discrimination explained $24 \%$ ( $R 2$ Change $=0.24, F$ Change $=32.52$, Sig. $F$ Change $p<0.001$ ).

Conclusions Indigenous adults who experienced racially-motivated housing discrimination in the past year had early and more pronounced wear and tear on neuroendocrine, cardiovascular, metabolic, and immune system functioning in young and middle adulthood than Indigenous peers who did not. These findings combine with others to highlight the need for increased efforts to prevent racially-motivated housing discrimination in urban centres.

\section{Background}

Racial discrimination is widely recognized as a fundamental social determinant of health for racialized groups [1]. To date, there has been limited information about the impacts that racially-motivated housing discrimination (HD), defined as HD motivated by race, ethnicity or color, may have on adult health. This examination is important given housing is an essential human resource and key determinant of health. Limiting access to housing can directly endanger the physical welfare of individuals by pushing them into substandard or unsafe living conditions, secondary homelessness (transient or emergency accommodation), and primary homelessness (no accommodation).

Racially-motivated HD is commonly experienced by minority populations. In the US, audits measuring HD across 5,500 paired tests in 30 urban areas found African Americans and Hispanics experienced consistent adverse discriminatory treatment in approximately $20-25 \%$ of housing rental or sales searches [2]. For renters this included receiving less information and fewer opportunities to view units; while home buyers received less assistance with financing and were steered into less wealthy communities by real estate agents. In Canada, studies in three cities have found that approximately a third of Indigenous adults experienced adverse discriminatory treatment in housing rental and sales searches [3-5]. For renters this included fewer opportunities to view units; being denied a rental application because of being Indigenous, and being told places were "just rented" when they had not been. For home buyers this included differential treatment from real estate agents and mortgage agencies [3]. In Australia, a sample of Indigenous adults living in Sydney described the search for housing as a battle, with racially-motivated discrimination from landlords and real estate agents repeatedly described as a key barrier to accessing this resource [6].

Several studies published by Yang and colleagues using data collected from approximately 10,000 adults living in 830 US neighbourhoods found racially-motivated HD was associated with reduced self-reported health, increased self-reported stress, and higher chronic disease and mental health disorder diagnoses [7-9]. Several qualitative and mixed methods studies have similarly highlighted impacts on mental and physical health. Nightingale (2016) interviewed post-secondary students in Canada about racial discrimination experienced while searching for or maintaining off-campus housing. Participants described how they avoided searching for housing in areas of the city that were "not ethnic friendly" even when those locations were closer to their school [10]. Forms of discrimination documented were similar to other studies, despite the expanded scope of ethnicities examined $[3,10,11]$. Motz et al. (2019) used the same dataset examined in the present study and found racially-motivated housing discrimination in 
the past year was associated with increased PTSD symptomology among Indigenous university students; particularly intrusive recollection [11]. In Australia, housing was described as a pervasive source of stress affecting the health of the whole Indigenous community in a city [6]. While social networks were used to avoid primary homelessness, participants indicated that discrimination directed at Indigenous people was contributing to long wait lists for social housing [6]. This resulted in secondary homelessness that was incredibly stressful for families, unsuitable for children, and created a sense of hopelessness and powerlessness to change the situation [6]. Participants across several studies also described the discrimination they faced after they were housed, such as receiving unequal maintenance services compared to other tenants and feeling pressured to move, and the stress and hopelessness they felt over this ongoing abuse of power $[3,6,10]$.

We theorize that the symptoms of mental distress reported by participants who experience racially-motivated HD may go beyond the mind to impact stress biology, thus serving as a pathway through which HD may get under the skin to impact the health outcomes reported by Yang and colleagues [7-9]. The human homeostatic system responds to a wide variety of environmental and social stressors by producing hormonal and neurotransmitter mediators that set appropriate physiologic responses in motion [12]. Yet some stressors, particularly those that threaten survival by creating uncertainty about access to essential human resources like housing, may perturb the body in ways that result in a shift from a homeostatic to an allostatic state [13-15]. An allostatic state, sometimes called 'fight-or-flight', is an altered form of physiologic regulation designed to promote short-term survival in the face of significant threat to personal safety [12]. Allostasis involves overresponses across one or more biological markers in magnitude or duration, as well as multiple physiologic responses competing concurrently with one another in an effort to promote short-term survival $[15,16]$. This process is adaptive in the short-term, but chronic overresponding can lead to changes in the body's defended values, range, or diurnal pattern for an array of biomarkers (e.g., cortisol). As well, multiple physiologic responses competing concurrently with one another is inefficient in the longer term and can lead to the weathering of these systems $[15,17,18]$. Allostatic load (AL) is an aggregate measure of wear and tear on the body due to the chronic activation of allostasis [19]. Increased AL is a preclinical marker of the pathophysiologic processes that precede the onset of disease, and a 10year predictor of morbidity, all-cause mortality, and cause-specific mortality across young, middle and older age adults [20,21].

We posit that racially-motivated HD may serve as a triggering experience that could shift the body into chronic allostasis and thus increased allostatic load, given HD threatens access to an essential human resource by interfering with an individual's ability to achieve safe, stable, and appropriate shelter for themselves and their loved ones. To test this hypothesis, we examined whether racially-motivated $\mathrm{HD}$ experienced in the past 12 months was associated with increased $\mathrm{AL}$ in a relatively young sample (Mean age $=27.8$ years) of Indigenous adults attending university in a small urban centre. AL was operationalized using markers from the three biological domains that framed the original AL index (i.e., neuroendocrine, cardiovascular, metabolic), and an added immune marker [22].

\section{Methods}

The present analysis is based on a cross-sectional study that collected data on social determinants of Indigenous health among university students who identified as Indigenous and attended school in a small city in western Canada (Population size: 98,000). Data collection began in September 2015 and continued over 4 academic terms ending in April 2017. The final sample size was 150 Indigenous adults. Study procedures were approved by the Human Subjects Research Committee at the University of Lethbridge. Data analyzed for the present analysis are available from the corresponding author upon reasonable request.

\section{Indigenous Advisory Committee}

This study was conceptualized using a participatory action research framework [23]. An Indigenous Advisory Committee made up of key members of the Indigenous community in Lethbridge was assembled and worked with the research team to set study priorities and make data collection decisions. Through this work, it was determined that salivary rather than blood samples would be taken given blood is a sacred element in many Indigenous cultures and must be respected in ways that may be incompatible with scientific research. As saliva is also a substance that comes from the body, a system was put in place in consultation with Indigenous Knowledge Holders to ensure the wishes of participants were honored. The consent form provided participants the option of having their saliva samples returned to them upon analysis or to have their saliva samples included in an Indigenous ceremony led by an Elder that returned the samples to the Earth. 


\section{Procedures}

Participants were recruited using posters and ads placed in e-newsletters on campus.

Respondents were asked to confirm eligibility by email/phone (i.e., they identified as Indigenous, current post-secondary students, and 18 years or older). Participants then attended an on-campus study office to complete consent procedures, paper-and pencil surveys, and the physical assessments needed to calculate AL score (mean completion time $=90 \mathrm{~min}$ ) during standard office hours (9:00am - 4:00pm). To ensure sufficient participant recruitment, we needed to accommodate student course schedules and thus could not standardize a narrow window for data collection across participants, which may have been useful for some biomarkers examined (e.g., DHEA-S, CRP). Saliva samples were collected at 3 time points during this visit using the passive drool technique. Participants rinsed their mouth with water and the first sample was collected after completing a portion of the questionnaire. Remaining samples were taken 30 and 60 minutes later. Whole saliva samples were collected in a $2 \mathrm{ml}$ microcentrifuge tube using a Saliva Collection Aid (Salimetrics, State College, PA). During data collection, salivary samples were stored in the in-office freezer and then transferred to a $-80^{\circ} \mathrm{C}$ freezer. Participants were provided with supplies for collecting saliva samples at home for two days, as well contact information for the research assistant who collected data from them during the office visit. Participants were asked to call, email or text with questions, and coordinate a time for sample return.

At home, participants selected two consecutive days with similar wake/sleep times and collected a saliva sample at three time points: immediately upon wake-up, 30 minutes after wake-up, and before bed, and to record the times in which samples were taken on forms provided. Participants were instructed to place the swab under the tongue for three minutes and then place it in a prelabeled tube and put it in their freezer. When all six samples were collected, the participant contacted the research assistant to coordinate sample return. We used cortisol awakening response (CAR) expert consensus guidelines to increase at-home adherence including clearly explaining the importance of strict adherence to sampling times, emphasizing the importance of collecting sample S1 immediately upon awakening, encouraging participants to ask questions via text/email/phone, providing take-home instructions, having participants record data collection time points in a diary log, advising participants to place kits beside the bed for morning collection, and text messaging the evening before sampling to highlight instructions [24]. Participants returned the samples in an insulated lunch kit with a freezer pack given to them during the in-office visit. Samples received were transferred to a $-80^{\circ} \mathrm{C}$ freezer. Participants were given an honorarium of $\$ 50$ for in-office measures and $\$ 50$ for at-home measures.

\section{Measures}

Allostatic load (AL)

AL score was based on a composite of seven biomarkers across four biological domains:

1. Cardiovascular markers: Resting systolic and diastolic blood pressure were measured using a Life Source automated sphygmomanometer (Auto Control Medical, Mississauga, ON). The first was taken approximately 15 minutes after the participant arrived, once they had completed the consent process and answered the first part of the survey package in a seated position. This reading was discarded. Two additional readings were taken 15 and 30 minutes after the first while the participant was seated. These two measures were averaged.

2. Neuroendocrine markers included DHEA-S and CAR. All were analyzed in duplicate. As per manufacturer's suggestion for DHEA-S, the three in-office samples were pooled and mixed for analysis. To examine CAR, the wake-up (S1) and 30 minutes post wake-up (S2) samples taken at home on the second day were used to calculate the percent change in cortisol between S1 and S2. Day 1 at-home samples were not combined with Day 2 to produce an average because missing data were higher on Day 1. CAR represents the sharp rise in cortisol levels across the first 30-45 min following morning awakening. In healthy adults, the magnitude of CAR ranges between a 50-156\% [25]. The mean CAR magnitude in this study was 65.1\% (Table 1).

3. Metabolic markers included body mass index (BMI) and waist circumference. To calculate BMI, height and weight were measured to the nearest $0.5 \mathrm{~cm}$ using a Health $O$ Meter mechanical beam scale and stadiometer, and to the nearly $0.1 \mathrm{~kg}$ using a weighbeam scale; respectively. Waist circumference (WC) was measured at the top of the iliac crest, to the nearest $0.5 \mathrm{~cm}$. Although correlated (Pearson's $r=0.87$ in this sample), both measures were included in the AL score as each are independently associated with health risk. 
4. Immune marker. We measured CRP using the third in-office saliva sample.

Cortisol, DHEA-S, and CRP concentrations were assessed using enzyme-linked immunosorbent assays (ELISA) (Salimetrics, LLC., State College, PA). Average intra-assay variability was $3.9 \%$ for cortisol, $6.6 \%$ for DHEAS, and $4.3 \%$ for CRP. Average inter-assay variability was $9.2 \%$ for cortisol, $12.8 \%$ for DHEAS, and $8.3 \%$ for CRP. For CAR, all samples from the same participant were analyzed in the same plate, to minimize the effect of inter-assay variability. AL risk assessment was based on the distribution of the study sample for salivary CRP and DHEA by dividing the sample into sex-specific quartiles with high risk defined by the highest quartile for CRP and the lowest quartile for DHEA-S. As shown in Table 1, we used standard cutoffs for all other biomarkers [26,27]. Consistent with prior studies, one point was assigned if the variable was in the high-risk quartile and 0 if not. Scores were summed across each system type (neuroendocrine, metabolic, immune, and cardiovascular) to create a total score for AL.

\section{Racial discrimination}

The Experiences of Discrimination (EOD) Scale is a valid and reliable measure of self-reported racial discrimination that has been used across many ethnic groups [28]. The situation score is derived by counting the number of situations (1 to 9 ) in which racial discrimination was experienced. Previous research suggests Indigenous Canadians experience high levels of racial discrimination, and that a scale adjusted to measure experiences in the past 12 months is recommended to ensure sufficient variability $[4,29]$. Consistent with previous research, each question in the present study was worded as follows, with information in brackets reflecting words added, and X reflecting the situation tested: (In the past 12 months) have you experienced discrimination, been prevented from doing something, or been hassled or made to feel inferior at $X$ because of your (Aboriginal) race, ethnicity or colour? Internal consistency of the measure in this study was good (Cronbach's alpha $=0.82$ ). Racially-motivated HD was operationalized using the following adapted question from the EOD: In the past 12 months, have you experienced discrimination, or been hassled or made to feel inferior getting or maintaining housing because of your Aboriginal race, ethnicity, or color? Response options were $0=$ No and $1=$ Yes. [28].

\section{Covariates}

Exact age, gender, parenthood and income were collected as part of the survey package. Categories used to examine each covariate are outlined in Table 2.

\section{Missing data}

Data were collected from 150 participants, 35 of whom were removed from the analysis because they chose to not complete and/or return at-home samples. An additional 8 were removed because the timing of at-home sampling was completed in ways that did not follow procedure resulting in the inability to calculate valid CAR [24]. As well, two participants were removed for not completing questions about discrimination in the past 12 months, and one was removed for not reporting their age. There were no missing data on survey questions about gender or income The final sample size included in this analysis was $N=104$. Independent-samples t-tests confirmed the mean age, income, and HD experience of participants included and excluded from the analysis due to missing data were not statistically different, nor was the gender balance different between groups. We conducted a supplementary reanalysis of the main findings excluding CAR from the AL calculation, which reduced our ability to understand the impacts of housing discrimination on neuroendocrine function, but increased the sample size to $N=144$.

\section{Analysis strategy}

Bootstrapped linear regression models $(k=5000)$ examined the association between past-year HD (yes or no) and the continuous form of AL. Bias-corrected and accelerated $(\mathrm{BCa})$ bootstrap intervals were used to adjust for potential skew. Potential confounders were carefully considered and tested before inclusion in models to reduce model overfitting, and keeping in mind that analyses that follow the "more control variables is better" approach to improve causal inference have been debunked [30-33]. Thus, potential confounders were tested using individual regression models before entry into the main model. Those associated with $\mathrm{AL}$ at $p<0.10$ were retained [34] which included age, income, and parenthood; but not gender or marital status.

Previous studies have controlled for health-risk behavior and mental health when examining associations between discrimination and AL. We disagree with such an approach given racial discrimination predicts later mental health and health-risk behaviour 
problems in more than 30 longitudinal studies across a variety of ethnicities and age groups worldwide $[1,35,36]$. This large body of longitudinal evidence suggests mental health and health-risk behaviour should be examined as part of the causal chain linking various forms of racial discrimination to $\mathrm{AL}$ (i.e., as mediators), rather than noise that is controlled in statistical models. Controlling for such intermediate variables introduces bias by decomposing the total effect of $x$ on $y$ into its parts [32]. If that is the goal, one should conduct a mediation analysis [37]; however, such analyses can produce endogenous selection bias [38] and would require a larger sample size. All analyses were run using SPSS 25.0.

\section{Results}

\section{Sample characteristics}

Sample characteristics are shown in Table 2. All participants were adult post-secondary students and most (98.1\%) attended school full-time. Almost three quarters of the sample were female in keeping with higher proportions of female Indigenous students in Canadian universities [39]. The mean age was 27.8 years ( $S D=8.7$, range 18-57 years), which is somewhat lower than the mean age (32.1 years) of Indigenous people in Canada during this time frame [40]. Almost half the sample (42.9\%) had children. Most (72.2\%) identified as low-middle or low income. The mean AL score for this sample was 2.5 out of a possible 7 (SD 1.3 , range 0 to 6 ). The AL median and mode were both 2.0, and the AL skewness value was 0.5 suggesting the distribution of $A L$ scores were approximately symmetric.

The mean number of situations in which discrimination had been experienced in the past year was 2.3 (SD $=1.3$, range 0 to 7 situations). Overall, $16.8 \%$ of the sample had experienced racially-motivated discrimination while searching for or maintaining housing in the past 12 months. Students between the ages of 15-44 years and those with children were more likely to experience HD than other participants. Those who reported HD in the past year experienced discrimination across significantly more situations in the past year than those who had not (Mean $=5.1$ vs. 1.8 situations, independent samples $t=7.44, d f=101$, $p<0.001)$.

\section{Racially-motivated HD and AL}

The average AL score was $3.94(S D=1.14)$ among adults who experienced HD, which was almost double that of those who had not had this experience in the past year (Mean $A L=2.22, S D=1.14$, independent samples $t=5.71, d f=103, p<0.001)$. In a model adjusted for sociodemographics, adults who experienced racially-motivated HD in the past-year had AL scores that averaged 1.5 points higher than peers who had not (Table 3 - Model 2). The full model explained $36 \%$ of the variance in AL score, of which racially-motivated HD explained $24 \%\left(R^{2}\right.$ Change $=0.24, F$ Change $=32.52$, Sig. F Change $\left.p<0.001\right)$.

The impact of HD on AL may be due to heightened discrimination experienced in other situations in that time frame. To examine this, we computed the total number of situations discrimination had been experienced in the past year, excluding housing, and added this covariate to the model. The variance inflation factor (VIF) was 1.3 indicating that the variance of this new covariate was 1.3 times greater than it would be if it was linearly independent of the other variables in the analysis [41]. This is below generally recommended thresholds and suggests multicollinearity was not a significant concern [42]. Findings indicate no change in the strength or significance of the association between $\mathrm{HD}$ and $\mathrm{AL}$ when discrimination experienced in other situations in the year was controlled (Table 3 - Model 3).

\section{Supplementary analyses}

Table 3 outlines a reanalysis of the main findings excluding CAR from the AL calculation. This decreased our understanding of the impacts of HD on neuroendocrine function, but increased the sample size to $N=144$. The mean AL score for the sample when calculated without CAR was 1.8 out of a possible 6 (SD 1.3, range 0 to 5). Among Indigenous adults who had experienced raciallymotivated HD in the past year the average AL score, excluding CAR, was $2.77(S D=1.23)$, compared to an average AL score of 1.62 among Indigenous adults who had not had this experience in the past year $(S D=1.22$, independent samples $t=4.06, d f=144, p=$ 0.001). In an adjusted model (Table 3, Model 4) adults who experienced racially-motivated HD in the past-year had AL scores that averaged almost one point higher than their peers who had not. The full model explained $26 \%$ of the variance in $A L$ score, of which racially-motivated $\mathrm{HD}$ explained $10 \%\left(R^{2}\right.$ Change $=0.10, F$ Change $=16.10$, Sig. F Change $\left.p<0.001\right)$ when CAR was excluded from 
the AL calculation (Table 3 - Model 5). When past-year discrimination score (excluding housing) was added, the covariate was not associated with $A L$ in the presence of the other variables in the model (VIF = 1.4). HD remained significantly associated was a 0.80-point increase in AL score when discrimination experienced in other situations in that time frame were controlled (Table 3 Model 6).

\section{Discussion}

Racially-motivated housing discrimination was a risk factor associated with a 1.5-point increase in allostatic load (out of a possible 7 points) within a relatively young sample of Indigenous university students in Canada. The aggregate measure of AL used in this study suggests Indigenous adults who experienced racially-motivated HD had early and more pronounced wear and tear on neuroendocrine, cardiovascular, metabolic, and immune system functioning in young and middle adulthood than peers who did not. These findings corroborate previous research documenting an association between racial discrimination experienced across a variety of life situations and AL [34,43-45]. We add to this literature by demonstrating that a setting-specific form of racial discrimination - racially-motivated housing discrimination - was independently associated with AL score after accounting for other situations in which discrimination had been experienced in the same time period. AL is an aggregate preclinical marker of the pathophysiologic processes that precede the onset of disease, and a 10-year predictor of morbidity, all-cause mortality, and cause-specific mortality across young, middle and older age adults $[20,21]$. Thus, the increased AL observed among those who experienced HD in this study may serve as a key etiologic pathway that links housing discrimination to the adverse health outcomes associated with this experience in the literature [3,6-10,19-21].

Several explanations for the observed association between racially-motivated housing discrimination and AL are possible. Housing discrimination may have been perceived, consciously or unconsciously, as a significant threat to physical safety by participants, given housing is an essential resource for human survival, and HD creates uncertainty about whether one can secure and retain this resource for themselves and their family. Thus, housing discrimination may have perturbed the stress response system toward short-term survival and an allostatic state. This would explain higher AL among adults who experienced HD in this study, given AL is an aggregate measure of physiologic wear and tear due to the chronic activation of allostasis. It may also be posited that when motivated by race, housing discrimination becomes exceptionally threatening, given it is based on fixed features of an individual's physical appearance that cannot be easily modified. Thus, housing discrimination due to race would make it more difficult for an individual to control or moderate the situation and gain access to this resource. Qualitative findings by Motz \& Currie (2019) using the present dataset describe the blunt and deliberate racial discrimination Indigenous students faced in their search for housing. While students made attempts to moderate these impacts by, for example, withholding an Indigenous last name on the phone, many still faced prejudicial attitudes and racial discrimination when they arrived to view units in person that impeded their ability to secure a place to live [11].

It is also possible that higher AL scores among university students produced more housing discrimination. It is difficult to establish how individuals screening tenants for units would ascertain or be aware of AL scores in ways that would be consistent enough to produce the observed associations. As well, longitudinal research has linked adolescent experiences of racial discrimination between 16-18 years of age to elevated AL at age 20, thus suggesting a temporal sequence for these variables among young adults [45]. However, due to the cross-sectional nature of the data used in the present study, the hypothesized temporal sequence of the observed association between racially-motivated housing discrimination and AL remains tentative without further research.

\section{Strengths and limitations}

To date, few published studies have focused on the health impacts of setting-specific forms of racial discrimination; this study adds to much needed work in this area. Other strengths include guidance by an Indigenous Advisory Committee, the use of a validated measure of racial discrimination, and the use of a cumulative AL approach to examine the impact of HD on multisystem biological dysfunction. Limiting participants to post-secondary students provided a more homogeneous sample and reduced residual confounding due to educational attainment.

Limitations include use of a cross-sectional design which precludes inferences about causation and temporal sequence, more female than male participants, and a relatively small sample of participants that may not be generalizable to the general population. The frequency of HD was likely an underestimate as students were not asked if they still lived with their parents.

Page $7 / 15$ 
Approximately $30 \%$ of the sample was excluded from the analysis due to missing data. However, comparative analyses suggest those excluded did not differ on variables examined, and racially-motivated HD remained a significant predictor of AL when a modified version that involved the larger sample was used. Response bias due to self-report is a concern given discrimination is often implicit in nature and pervasive in society and may not always be consciously perceived [28]. Thus, self-reported discrimination may result in underreporting, revealing only a small portion of the actual effect of racial discrimination on the individual [46]. The use of a 12-month measure of discrimination may be a limitation as the heightened AL scores observed may have been a result of HD experienced over a longer time period. Due to the small sample size, a limited number of covariates could be controlled in statistical models, which may have resulted in residual confounding [33]. In terms of generalizability, more than half of all Indigenous Canadians aged 25-64 years have a post-secondary qualification, including 34\% who have completed university or college [47]. That said, the Indigenous Advisory Committee who guided this study suggested Indigenous university students may be more resilient than the general population, given many have had to overcome significant hardships to enroll and attend; and all have at least a high school education. While the present sample provided a good test of the hypothesis that raciallymotivated housing discrimination may impact AL given it may be more resilient, studies are needed to determine whether the observed association would be more pronounced within less resilient and/or educated populations.

\title{
Conclusion
}

Indigenous university students who experienced racially-motivated housing discrimination had early and more pronounced wear and tear on neuroendocrine, cardiovascular, metabolic, and immune system functioning in young and middle adulthood than peers who did not. These findings combine with others to highlight the need for increased efforts to prevent racially-motivated housing discrimination in urban centres.

\section{Abbreviations}

\author{
AL = Allostatic load \\ $\mathrm{BCa}=$ Bias-corrected and accelerated \\ $\mathrm{BMI}=$ Body mass index \\ $\mathrm{CAR}=$ Cortisol awakening response \\ $\mathrm{CC}=$ Cultural continuity \\ CRP $=$ C-Reactive Protein \\ DHEA-S = dehydroepiandrosterone sulfate \\ EOD $=$ Experiences of discrimination \\ DBP = Diastolic blood pressure \\ $\mathrm{HD}=$ Housing discrimination \\ HPA = hypothalamic-pituitary-adrenal \\ LOWESS = locally weighted scatterplot smoother \\ SAM = sympathetic-adrenal-medullary \\ $\mathrm{SBP}=$ systolic blood pressure \\ $\mathrm{VI}=$ Vancouver Index \\ $\mathrm{VIF}=$ Variance inflation factor
}


$\mathrm{WI}=$ waist circumference

\section{Declarations}

Ethics approval and consent to participate: This study was reviewed and approved by the Human Research Ethics Board in the Office of Research Ethics at the University of Lethbridge (Protocol \#2014-046). All participants provided informed written consent.

Consent for publication: Not applicable

Availability of data and materials: The dataset analysed during the current study are available from the corresponding author on reasonable request.

Competing interests: All authors report no conflicts of interest.

Funding: This study was funded by an operating grant from the Institute of Aboriginal Peoples Health within the Canadian Institutes of Health Research (Funding Reference Number: 131590, PI: Currie, CL). Dr. Currie was supported by an Alberta Innovates Translational Health Chair in Aboriginal Health \& Wellbeing during the course of this research.

Authors' contributions: CC and JL designed the study and acquired the data. CC analyzed and interpreted the data, and drafted the manuscript. TM and JL reviewed the manuscript and provided feedback. All authors reviewed and approved the final manuscript.

Acknowledgements: The authors wish to thank members of the Indigenous Advisory Committee who provided input on the development of the larger project from which this study was based, and the Indigenous students who shared their experiences and perspectives with us.

\section{References}

1. Paradies Y, Ben J, Denson N, Elias A, Priest N, Pieterse A, et al. Racism as a determinant of health: a systematic review and meta-analysis. Hills RK, editor. PLoS One [Internet]. 2015 [cited 2018 Oct 2];10:e0138511. Available from: http://dx.plos.org/10.1371/journal.pone.0138511

2. Turner M. et al. Discrimination in metropolitan housing markets: national results from Phase 1 HDS 2000 [Internet]. Washington, DC; 2002. Available from: https://www.urban.org/sites/default/files/publication/60776/410821-Discriminationin-Metropolitan-Housing-Markets.PDF

3. Cohen I. Housing discrimination and Aboriginal people in Winnipeg and Thompson, Manitoba [Internet]. Ottawa, ON; 2004. Available from: http://publications.gc.ca/site/eng/391207/publication.html

4. Currie C, Wild T, Schopflocher DP, Laing L, Veugelers P. Racial discrimination experienced by Aboriginal university students in Canada. Can. J. Psychiatry. [Internet]. 2012 [cited 2013 Apr 25];57:617-25. Available from: http://www.ncbi.nlm.nih.gov/pubmed/23072953

5. Currie CL, Wild TC, Schopflocher DP, Laing L, Veugelers PJ, Parlee B. Racial Discrimination, Post Traumatic Stress, and Gambling Problems among Urban Aboriginal Adults in Canada. J. Gambl. Stud. 2012;

6. Andersen MJ, Williamson AB, Fernando P, Redman S, Vincent F. "There's a housing crisis going on in Sydney for Aboriginal people": focus group accounts of housing and perceived associations with health. BMC Public Health [Internet]. BioMed Central; 2016 [cited 2019 Jun 29];16:429. Available from: http://www.ncbi.nlm.nih.gov/pubmed/27220748

7. Yang T-C, Chen I-C, Kim S, Choi S. Differential investments and opportunities: How do neighborhood conditions moderate the relationship between perceived housing discrimination and social capital? Soc. Sci. Res. [Internet]. 2018 [cited 2018 Oct 4];72:69-83. Available from: https://linkinghub.elsevier.com/retrieve/pii/S0049089X17306555

8. Yang T-C, Chen D, Park K. Perceived Housing Discrimination and Self-Reported Health: How Do Neighborhood Features Matter? Ann. Behav. Med. [Internet]. 2016 [cited 2018 Oct 4];50:789-801. Available from: https://academic.oup.com/abm/article/50/6/789-801/4562657

9. Yang T-C, Park K. To what extent do sleep quality and duration mediate the effect of perceived discrimination on health? Evidence from Philadelphia. J. Urban Heal. [Internet]. Springer US; 2015 [cited 2019 Jul 4];92:1024-37. Available from: 
http://link.springer.com/10.1007/s11524-015-9986-8

10. Nightingale C. "It was easy to look for a place, but hard to actually get one": University students' experiences of racial discrimination in off-campus housing (Master of Arts) [Internet]. Brock University; 2016. Available from: https://dr.library.brocku.ca/handle/10464/10413

11. Motz TA, Currie CL. Racially-motivated housing discrimination experienced by Indigenous postsecondary students in Canada: impacts on PTSD symptomology and perceptions of university stress. Public Health [Internet]. 2019;in press. Available from: https://www.sciencedirect.com/science/article/pii/S0033350618304001

12. McEwen, B.; Seeman T. Allostatic load and allostatis [Internet]. San Francisco, CA; 2009. Available from: https://macses.ucsf.edu/research/allostatic/allostatic.php

13. Karatsoreos IN, McEwen BS. Psychobiological allostasis: resistance, resilience and vulnerability. Trends Cogn. Sci. [Internet]. 2011 [cited 2019 May 25];15:576-84. Available from: https://linkinghub.elsevier.com/retrieve/pii/S1364661311002208

14. Cabanac M. Adjustable set point: to honor Harold T. Hammel. J. Appl. Physiol. [Internet]. 2006 [cited 2019 May 25];100:133846. Available from: http://www.physiology.org/doi/10.1152/japplphysiol.01021.2005

15. Ramsay DS, Woods SC. Clarifying the roles of homeostasis and allostasis in physiological regulation. Psychol. Rev. [Internet]. NIH Public Access; 2014 [cited 2019 May 25];121:225-47. Available from: http://www.ncbi.nlm.nih.gov/pubmed/24730599

16. Peters A, McEwen BS. Introduction for the allostatic load special issue. Physiol. Behav. [Internet]. 2012 [cited 2019 May 25];106:1-4. Available from: http://www.ncbi.nlm.nih.gov/pubmed/22226993

17. Edwards S, Koob GF. Neurobiology of dysregulated motivational systems in drug addiction. Future Neurol. [Internet]. 2010 [cited 2019 May 25];5:393-410. Available from: https://www.futuremedicine.com/doi/10.2217/fnl.10.14

18. Koob GF, Le Moal M. Plasticity of reward neurocircuitry and the "dark side" of drug addiction. Nat. Neurosci. [Internet]. 2005 [cited 2019 May 25];8:1442-4. Available from: http://www.nature.com/articles/nn1105-1442

19. McEwen BS. Stress, adaptation, and disease: allostasis and allostatic load. Ann. N. Y. Acad. Sci. [Internet]. 1998 [cited 2018 Aug 22];840:33-44. Available from: http://doi.wiley.com/10.1111/j.1749-6632.1998.tb09546.x

20. Robertson T, Beveridge G, Bromley C. Allostatic load as a predictor of all-cause and cause-specific mortality in the general population: Evidence from the Scottish Health Survey. Abe T, editor. PLoS One [Internet]. Public Library of Science; 2017 [cited 2018 Oct 2];12:e0183297. Available from: http://dx.plos.org/10.1371/journal.pone.0183297

21. McEwen BS. Physiology and Neurobiology of Stress and Adaptation: Central Role of the Brain. Physiol. Rev. 2007;87:873904.

22. Juster R-P, McEwen BS, Lupien SJ. Allostatic load biomarkers of chronic stress and impact on health and cognition. Neurosci. Biobehav. Rev. [Internet]. 2010 [cited 2018 Oct 2];35:2-16. Available from: http://www.ncbi.nlm.nih.gov/pubmed/19822172

23. McTaggert R. Principles for participatory action research. Adult Educ. Q. [Internet]. McTaggert, Robin: Deakin U, Geelong, Vict, Australia: Sage Publications; 1991;41:168-87. Available from: http://dx.doi.org/10.1177/0001848191041003003

24. Stalder T, Kirschbaum C, Kudielka BM, Adam EK, Pruessner JC, Wüst S, et al. Assessment of the cortisol awakening response: Expert consensus guidelines. Psychoneuroendocrinology [Internet]. 2016 [cited 2018 Oct 2];63:414-32. Available from: https://linkinghub.elsevier.com/retrieve/pii/S0306453015009580

25. Clow A, Thorn L, Evans P, Hucklebridge F. The awakening cortisol response: methodological issues and significance. Stress [Internet]. 2004 [cited 2018 Oct 10];7:29-37. Available from: http://www.ncbi.nlm.nih.gov/pubmed/15204030

26. Juster R-P, Moskowitz DS, Lavoie J, D’Antono B. Sex-specific interaction effects of age, occupational status, and workplace stress on psychiatric symptoms and allostatic load among healthy Montreal workers. Stress [Internet]. Taylor \& Francis; 2013 [cited 2018 Feb 4];16:616-29. Available from: http://www.tandfonline.com/doi/full/10.3109/10253890.2013.835395

27. Gustafsson PE, San Sebastian M, Janlert U, Theorell T, Westerlund H, Hammarström A. Life-course accumulation of neighborhood disadvantage and allostatic load: empirical integration of three social determinants of health frameworks. Am. J. Public Health [Internet]. American Public Health Association; 2014 [cited 2018 Feb 4];104:904-10. Available from: http://ajph.aphapublications.org/doi/10.2105/AJPH.2013.301707

28. Krieger N, Smith K, Naishadham D, Hartman C, Barbeau EM. Experiences of discrimination: validity and reliability of a selfreport measure for population health research on racism and health. Soc Sci Med. 2005;61:1576-96. 
29. Currie CL, Wild TC, Schopflocher D, Laing L. Racial discrimination, post-traumatic stress and prescription drug problems among Aboriginal Canadians. Can. J. Public Heal. 2015;106:e382-7.

30. Spector PE, Brannick MT. Methodological Urban Legends: The Misuse of Statistical Control Variables. Organ. Res. Methods [Internet]. 2011 [cited 2019 Jul 11];14:287-305. Available from:

http://journals.sagepub.com/doi/10.1177/1094428110369842

31. Achen $\mathrm{CH}$. Let's put garbage-can regressions and garbage-can probits where they belong. Confl. Manag. Peace Sci. [Internet]. 2005 [cited $2019 \mathrm{Jul}$ 11];22:327-39. Available from: http://journals.sagepub.com/doi/10.1080/07388940500339167

32. Rohrer JM. Thinking Clearly About Correlations and Causation: Graphical Causal Models for Observational Data. Adv. Methods Pract. Psychol. Sci. [Internet]. SAGE PublicationsSage CA: Los Angeles, CA; 2018 [cited 2019 Jul 11];1:27-42. Available from: http://journals.sagepub.com/doi/10.1177/2515245917745629

33. Babyak MA. What You See May Not Be What You Get: A Brief, Nontechnical Introduction to Overfitting in Regression-Type Models. Psychosom. Med. From Duke University Medical Center, Durham, NC.; 2004;66:411-21.

34. Allen AM, Thomas MD, Michaels EK, Reeves AN, Okoye U, Price MM, et al. Racial discrimination, educational attainment, and biological dysregulation among midlife African American women. Psychoneuroendocrinology [Internet]. Pergamon; 2019 [cited 2018 Oct 1];99:225-35. Available from: https://www.sciencedirect.com/science/article/pii/S0306453018301215

35. Assari S, Moazen-Zadeh E, Caldwell CH, Zimmerman MA. Racial Discrimination during Adolescence Predicts Mental Health Deterioration in Adulthood: Gender Differences among Blacks. Front. public Heal. [Internet]. Frontiers Media SA; 2017 [cited 2019 May 29];5:104. Available from: http://www.ncbi.nlm.nih.gov/pubmed/28611972

36. Assari S, Mistry R, Lee DB, Caldwell CH, Zimmerman MA. Perceived Racial Discrimination and Marijuana Use a Decade Later; Gender Differences Among Black Youth. Front. Pediatr. [Internet]. 2019 [cited 2019 May 29];7:78. Available from: http://www.ncbi.nlm.nih.gov/pubmed/30968004

37. Hayes AF, Little TD. Introduction to mediation, moderation, and conditional process analysis: a regression-based approach [Internet]. First Edit. 2013 [cited 2018 Oct 7]. Available from: http://afhayes.com/introduction-to-mediation-moderation-andconditional-process-analysis.html

38. Elwert F, Winship C. Endogenous selection bias: the problem of conditioning on a collider variable. Annu. Rev. Sociol. [Internet]. Annual Reviews; 2014 [cited 2019 Jul 11];40:31-53. Available from: http://www.annualreviews.org/doi/10.1146/annurev-soc071913-043455

39. Ferrao V. Women in Canada: a gender based statistical report [Internet]. Statistics Canada; 2010. Available from: http://www.statcan.gc.ca/pub/89-503-x/2010001/article/11387-eng.htm

40. Statistics Canada. Aboriginal peoples in Canada: Key results from the 2016 Census. Statistics Canada Catalogue no. 11-001-X [Internet]. Ottawa, ON; 2017. Available from: dq171025a-eng.pdf (Portable Document Format (PDF), 473.70kB)

41. O’Brien RM. A Caution Regarding Rules of Thumb for Variance Inflation Factors. Qual. Quant. [Internet]. Springer Netherlands; 2007 [cited 2019 Aug 1];41:673-90. Available from: http://link.springer.com/10.1007/s11135-006-9018-6

42. Akinwande MO, Dikko HG, Samson A, Akinwande MO, Dikko HG, Samson A. Variance Inflation Factor: As a Condition for the Inclusion of Suppressor Variable(s) in Regression Analysis. Open J. Stat. [Internet]. Scientific Research Publishing; 2015 [cited 2019 Aug 1];05:754-67. Available from: http://www.scirp.org/journal/doi.aspx?DOI=10.4236/ojs.2015.57075

43. Cuevas AG, Wang K, Williams DR, Mattei J, Tucker KL, Falcon LM. The association between perceived discrimination and allostatic load in the Boston Puerto Rican Health Study. Psychosom. Med. [Internet]. 2019 [cited 2019 Jul 24];1. Available from: http://www.ncbi.nlm.nih.gov/pubmed/31145378

44. Ong AD, Williams DR, Nwizu U, Gruenewald TL. Everyday unfair treatment and multisystem biological dysregulation in African American adults. Cult. Divers. Ethn. Minor. Psychol. [Internet]. 2017 [cited 2018 Oct 1];23:27-35. Available from: http://doi.apa.org/getdoi.cfm?doi=10.1037/cdp0000087

45. Brody GH, Lei M-K, Chae DH, Yu T, Kogan SM, Beach SRH. Perceived Discrimination Among African American Adolescents and Allostatic Load: A Longitudinal Analysis With Buffering Effects. Child Dev. [Internet]. 2014 [cited 2019 Jan 10];85:989-1002. Available from: http://doi.wiley.com/10.1111/cdev.12213

46. Berger M, Sarnyai Z. "More than skin deep": stress neurobiology and mental health consequences of racial discrimination. Stress [Internet]. 2015 [cited 2018 Oct 1];18:1-10. Available from: 
http://www.tandfonline.com/doi/full/10.3109/10253890.2014.989204

47. Government of Canada. Education in Canada: Key results from the 2016 Census [Internet]. 2017. Available from: https://www150.statcan.gc.ca/n1/daily-quotidien/171129/dq171129a-eng.pdf

\section{Tables}

Table 1. Mean, range and cut-points used for allostatic load (AL) biomarkers $(N=104)$ *

\begin{tabular}{|c|c|c|c|c|c|}
\hline Biomarker & Range & Mean & $\mathrm{SD}$ & $\begin{array}{l}\text { Cut-point } \\
\text { female }\end{array}$ & $\begin{array}{l}\text { Cut-point } \\
\text { male }\end{array}$ \\
\hline \multicolumn{6}{|l|}{ 1. Cardiovascular } \\
\hline Resting SBP (mm Hg) & 90,150 & 119.1 & 13.0 & $>140$ & $>140$ \\
\hline Resting DBP (mm Hg) & 59,111 & 78.0 & 10.3 & $>90$ & $>90$ \\
\hline \multicolumn{6}{|l|}{ 2. Neuroendocrine } \\
\hline DHEA-S $(\mu \mathrm{g} / \mathrm{dL})$ & $\begin{array}{l}\text { 188.5 } \\
16055.6\end{array}$ & 4247.0 & 3743.0 & $<1419.5$ & $<2865.1$ \\
\hline CAR & $-98.8,771.7$ & 65.1 & 165.4 & $\begin{array}{l}<50.0 \text { or } \\
>156.0\end{array}$ & $<50.0$ or 156.0 \\
\hline \multicolumn{6}{|l|}{ 3. Metabolic } \\
\hline BMI $\left(\mathrm{kg} / \mathrm{m}^{2}\right)$ & $18.8,48.5$ & 29.0 & 6.5 & $>30.0$ & $>30.0$ \\
\hline $\begin{array}{l}\text { Waist circumference } \\
(\mathrm{cm})\end{array}$ & $68.9,166.4$ & 97.9 & 18.1 & $>88.0$ & $>102.0$ \\
\hline $\begin{array}{l}\text { 4. Immune } \\
\text { C-Reactive Protein } \\
(\mathrm{pg} / \mathrm{ml})\end{array}$ & $55.1,3150.0$ & 481.9 & 666.9 & $>397.8$ & $>711.8$ \\
\hline Total AL Score & $0-6$ & 2.5 & 1.3 & & \\
\hline
\end{tabular}

*SBP = systolic blood pressure; DBP = diastolic blood pressure DHEA-S= dehydroepiandrosterone-sulfate; CAR= cortisol awakening response; $\mathrm{BMI}=$ body mass index.

Table 2. Characteristics of the sample

\begin{tabular}{lr}
\hline Characteristics & Total $\boldsymbol{N}(\%)$ \\
\hline Total Sample & $104(100 \%)$ \\
Gender & $77(73.3)$ \\
$\quad$ Female & $28(26.7)$ \\
$\quad$ Male & \\
Age & $47(44.8)$ \\
18-24 years & $36(34.3)$ \\
25-34 years & $17(16.2)$ \\
35-44 years & $5(4.8)$ \\
45+ years & $7(6.7)$ \\
Income group & $26(24.8)$ \\
Upper-middle/upper income & $51(48.6)$ \\
Upper-middle/middle & $21(20.0)$ \\
Lower-middle & \\
Low income & $45(42.9)$ \\
Have children & $60(57.1)$ \\
$\quad$ Yes & \\
$\quad$ No & \\
\hline
\end{tabular}


Table 3. Linear regression models for the direct effects of racially-motivated HD and covariates on allostatic load score calculated with (Models 1-3) and without CAR (Models 4-6)* 


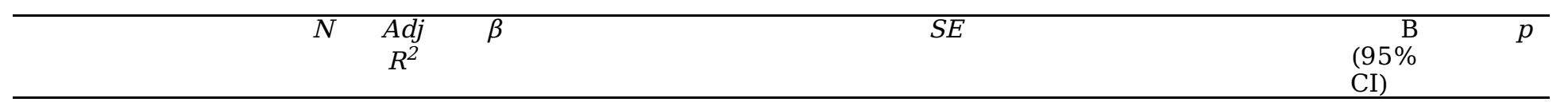

Model 1: Unadj. 104

estimates

$\begin{array}{lcc}\text { Past-year HD } & 0.23 & 0.49 \\ \text { Age } & 0.17 & 0.42 \\ \text { Income } & 0.04 & -0.22 \\ & & \\ \text { Have children } & 0.09 & 0.81\end{array}$
$0.30 \quad 1.73 \quad 0.001$ (1.13, 2.32)
$0.01 \quad 0.06 \quad 0.001$ $(0.04$, $0.09)$
$-0.15 \quad-0.35$ $(-0.65$, $-0.04)$
$\begin{array}{lll}0.25 & 0.84 & 0.01\end{array}$
(0.35, 1.33)

Model 2: Adj. for $104 \quad 0.36$

sociodemographics

Past-year HD

Age

0.38

Income

$-0.12 \quad 0.13$

Have children

$-0.10$

Model 3: Adj. for

$103 \quad 0.35$

sociodemographics

$\&$ other

discrimination

Past-year HD

0.44

Other past-year discrimination

Age

0.38

Income

$-0.12 \quad 0.13$

Have children

$-0.10$

Model 4: Unadj.

144

estimates

Past-year HD

$$
0.10 \quad 0.32
$$

Age

0.18

0.43

Income

$0.03 \quad-0.20$

Have children

$0.04 \quad 0.22$

$$
\begin{aligned}
& 0.29 \quad 1.51 \quad 0.001 \\
& 0.02 \quad 0.06 \quad 0.001
\end{aligned}
$$
$\begin{array}{lll}0.32 & 1.50 & 0.001\end{array}$ (0.87, 2.14)
$0.06 \quad 0.01$ $(-0.13$, $0.74)$ $\begin{array}{lll}0.02 & 0.06 & 0.001\end{array}$ (0.03, $0.09)$ $-0.19$ $(-0.45$,
$\begin{array}{ll}0.29 & 0.07) \\ 0.0 .26\end{array}$ $(-0.82$, $0.31)$
0.16
0.38
0.98

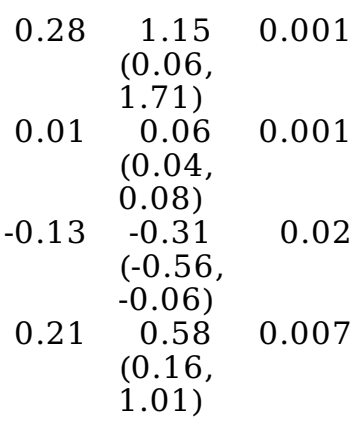

Model 5: Adj. for $144 \quad 0.26$ sociodemographics

Past-year HD 
(0.04,

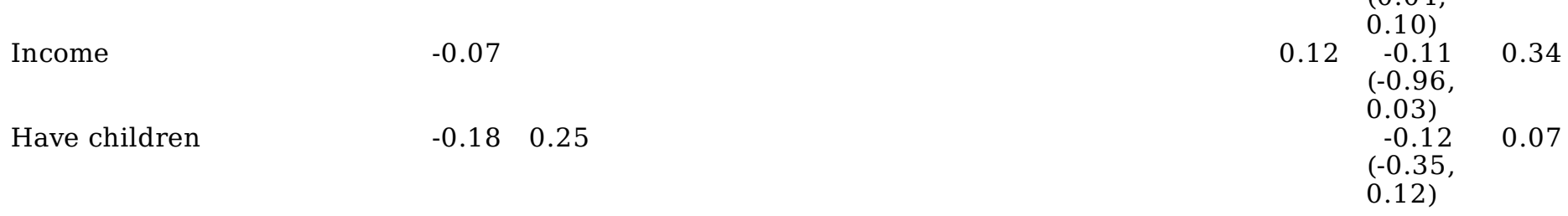

Model 6: Adj. for $142 \quad 0.26$

sociodemographics

$\&$ other

discrimination

Past-year HD

0.22

$0.30 \quad 0.80$

$(0.20$

0.01

Other past-year

0.10

1.40)

discrimination

0.48

\begin{tabular}{ll}
$0.06 \quad 0.07$ \\
\hline
\end{tabular}

0.22

Age

$0.01 \quad 0.07$
0.04

$0.19)$

$(0.04$,

Income $\quad-0.08$

$0.10)$

Have children $\quad-0.20$ $(-0.36$

0.30

$0.11)$

$0.26-0.52$

$(-1.02$,

0.05 $-0.01)$

$* \beta$ is the standardized beta weight, $\mathrm{B}$ is the unstandardized beta weight. $\mathrm{CAR}=$ cortisol awakening response 